\title{
Acute kidney injury in liver transplant candidates: A position paper on behalf of the LIVER INTENSIVE CARE GROUP of EUROPE
}

Paolo ANGELI, Dimitri BEZINOVER, Gianni BIANCOFIORE, Anja BIENHOLZ, James FINDLAY, Catherine PAUGAM BURTZ, Koen REYNTJENS, Tetsuro SAKAI, Fuat Hakan SANER, Dana TOMESCU, Gebhard WEGENER, Emmanuel WEISS

Minerva Anestesiol 2016 Oct 19 [Epub ahead of print]

\section{MINERVA ANESTESIOLOGICA}

Rivista di Anestesia, Rianimazione, Terapia Antalgica e Terapia Intensiva pISSN 0375-9393 - eISSN 1827-1596

Article type: Review Article

The online version of this article is located at http://www.minervamedica.it

Subscription: Information about subscribing to Minerva Medica journals is online at:

http://www.minervamedica.it/en/how-to-order-journals.php

Reprints and permissions: For information about reprints and permissions send an email to:

journals.dept@minervamedica.it - journals2.dept@minervamedica.it - journals6.dept@minervamedica.it 
Acute kidney injury in liver transplant candidates: A position paper on behalf of the LIVER INTENSIVE CARE GROUP of EUROPE

Authors (in alphabetical order)

Paolo Angeli ${ }^{1}$, Dimitri Bezinover ${ }^{2}$, Gianni Biancofiore ${ }^{3}$, Anja Bienholz ${ }^{4}$, James Findlay, ${ }^{5}$

Catherine Paugam Burtz ${ }^{6}$, Koen Reyntjens ${ }^{7}$, Tetsuro Sakai ${ }^{8}$, Fuat H. Saner ${ }^{9}$, Dana

Tomescu $^{10}$, Gebhard Wagener ${ }^{11}$ Emmanuel Weiss ${ }^{6}$

\section{Affiliations}

1. Department of Medicine, Hepatology Unit, University School of Medicine, Padova, Italy

2. Department of Anesthesiology, Penn State Hershey Medical Center, Hershey, PA, USA

3. Department of Transplant Anesthesia and Critical Care, Azienda Ospedaliera-Universitaria Pisa, Italy

4. Department of Nephrology, University Duisburg-Essen, Germany

5. Department of Anesthesiology, Mayo Clinic, Rochester, MN, USA

6. Department of anesthesia and Critical care, APHP Hopital Beaujon, Paris and University Paris Diderot-Paris 7, PARIS, France

7.Department of Anesthesia, University Medical Center, Groningen, University of Groningen, Netherlands

8. Department of Anesthesiology, University of Pittsburgh Medical Center, Pittsburgh, PA, USA

9. Department of General, Visceral, and Transplant Surgery, University Duisburg-Essen, Germany 
10. Department of Anesthesiology and Critical Care, Fundeni Clinical Institute, Bucharest, Romania

11. Gebhard Wagener, Department of Anesthesiology, University of Columbia, New York, NY, USA

\section{Correspondence to:}

dr. Prof Fuat H. Saner

Department of General- and Visceral- and Transplant Surgery

Hufelandstr. 55. 45147 Essen

Tel: 004920172384008

Fax: 00492017231145

Email: fuat.saner@uni-due.de

Key words:

cirrhosis, liver transplantation, acute kidney failure, timing dialysis

Word account: 4,203

All authors contributed on an equal basis to important tasks such as literature research, drafting the work, writing a section, and/or revising the work for important content; gave their final approval; and agreed that all parts of the manuscript ensure integrity and appropriate investigation at all parts of the manuscript 


\section{ABSTRACT}

Acute kidney injury (AKI) is associated with high perioperative mortality. A series of AKI research breakthroughs are worth mentioning. First, in 2003, serum and urine biomarkers specific to AKI were identified. These biomarkers have contributed to early detection, prevention, and treatment of AKI. In 2004, AKI severity was defined with the Risk, Injury, Failure, Loss, and End-stage kidney disease (RIFLE) criteria, which was developed by the International Consensus Conference Workgroup of the Acute Dialysis Quality Initiative. In 2007, the definition was further refined by the AKI network classification, and in 2012 Kidney Disease Improving Global Outcomes (KDIGO) standardized the RIFLE criteria into AKI stages I to III. Finally, a definition of AKI specifically for patients with end-stage liver disease (ESLD) was established by the International Club of Ascites (ICA) in 2015. Overall, these definitions and standardized criteria provide a foundation for systematic management of patients with AKI.

Another important challenge over the last 20 years in the management of AKI is establishing the optimum timing to initiate renal replacement therapy (RRT). Previous evaluations did not support the use of RRT at the early stage of kidney dysfunction. Although a number of retrospective studies published in the last 10 to 15 years support using RRT at an early stage for patients with AKI, the exact indication for RRT remains unclear.

Abstract word count: 219 


\section{Introduction}

Acute kidney injury (AKI) is associated with significantly increased short- and longterm complications, increased mortality, and high healthcare costs ${ }^{1}$; the reported incidence of this condition after liver transplantation (LT) is as high as $70 \%{ }^{2}$.

Extensive research on AKI over the last 20 years has significantly advanced our understanding of this condition. In particular, perioperative risk factors associated with the development of AKI in LT candidates have been identified and preventive strategies and treatments have been developed. It is now possible for medical practitioners to recognize and manage AKI earlier. Another important challenge in this field over the last 20 years is establishing the optimum timing to initiate renal replacement therapy (RRT).

The aim of this position paper is to provide an up-to-date overview of AKI in patients with end-stage liver disease (ESLD) with special emphases on diagnosis using biomarkers, risk factors, and treatment.

\section{Methods}

In order to provide the clinical community with a straightforward and updated document about a debated and controversial topic, the Liver Intensive Care Group of Europe (LICAGE) nominated a panel of well-recognized international experts who reviewed the available clinical literature and produced practical clinical recommendations. The initial draft was revised by all of the panel members so that the final version resulted from the consensus of the entire working group. A systematic PubMed literature search on kidney failure related to cirrhosis and/or TL published from 1990 to January 2016 was performed, focusing on most relevant studies. The level of evidence and strength of recommendation were judged 
according to the Grading of Recommendations Assessment Development and Evaluation system. The strength of the evidence was classified into four levels: high (A), moderate (B), low (C), and very low (D) quality evidence, while that of the recommendations was divided into two: strong (1) and weak (2). If no clear evidence existed, the recommendations were based on the consensus advice of the writing committee and the expert opinion(s) reported in the literature.

\section{Pathophysiology of AKI in patients with ESLD}

Portal hypertension $(\mathrm{PH})$ is one of most important pathophysiological mechanisms responsible for the development of AKI in patients with ESLD. PH is associated with significant modulations of splanchnic circulation and triggers systemic vasodilatation with reduced central blood volume ${ }^{3}$. This leads to a drop in mean arterial pressure with subsequent activation of the renin-angiotensin-aldosterone system and the sympathetic nervous system, elevated release of vasopressin from the pituitary gland ${ }^{4}$, and increased cardiac output; all of these signs are implicated in producing hyperdynamic circulation that is similar to sepsis-type hemodynamics ${ }^{5}$. These complex hemodynamic changes are responsible for histological myocardial modulation with subsequent systolic and diastolic dysfunction, defined as cirrhotic cardiomyopathy ${ }^{6}$.

Due to reduced renal perfusion, the glomerular filtration rate (GFR) decreases, with subsequent release of aldosterone and renin as well as increased release of vasopressin ${ }^{7,8}$. All these changes, in combination with low colloid osmotic pressure, result in water retention, ascites, fluid overload, and increased vasoconstriction of the vas afferent vessels of the kidney. This leads to a further reduction in renal perfusion, which puts the patient at great risk of developing hepatorenal syndrome (HRS) ${ }^{9}$. 
The systemic inflammatory response also plays a crucial role in the development of AKI in patients with ESLD. These patients appear to be more susceptible to systemic infection than patients without ESLD, and a number of pathophysiologic mechanisms contribute to this effect. Patients with ESLD have increased lipopolysaccharides and tumor necrosis factor- $\alpha$ serum levels, which cause splanchnic dilatation ${ }^{10}$. These increased levels, in combination with a decreased local immune response, damage the intestinal mucosa and alter local gut-associated lympathic tissue function. This leads to increased bacterial translocation ${ }^{11}$. Another mechanism responsible for generalized inflammation is associated with ischemia-reperfusion injury during LT. The affected hepatocytes release nuclear or cytosolic proteins called damage-associated molecular patterns (DAMPs), which can induce inflammation ${ }^{12}$. One DAMP, high-mobility group box-1 (HMGB1), is associated with a inflammatory response and interacts with toll-like receptors, thereby causing renal injury ${ }^{12}$.

It should be noted that a number of other factors can lead to kidney injury in this patient population. These include medications (e.g., nonsteroidal anti-inflammatory drugs [NSAIDs]), diuretics, angiotensin-converting enzyme) and factors that can cause hypovolemia, such as gastrointestinal bleeding or paracentesis without volume replacement 13.

Furthermore, the risk factors for AKI in patients with ESLD are nearly the same as those for developing HRS ${ }^{14}$. It has been demonstrated that even a minor improvement in regard to GFR is associated with a higher patient survival rate ${ }^{15}$.

\section{Diagnostic insights of AKI in patients with ESLD}

For almost 20 years, acute renal failure in patients with ESLD was defined, according to an ICA criterion, as an increase in serum creatinine ( $\mathrm{sCr}$ ) of $50 \%$ from baseline to a final 
value $>1.5 \mathrm{mg} / \mathrm{dL}(133 \mu \mathrm{mol} / \mathrm{L}){ }^{16,17}$. Presently, however, ICA experts recommend using the Kidney Disease Improving Global Outcomes (KDIGO) criteria, which are based on changes in $\mathrm{sCr}$, to define AKI (Table 1) ${ }^{18}$. The definition of AKI in patients with ESLD includes an abrupt reduction in kidney function demonstrated by either an absolute increase in $\mathrm{sCr}$ of at least $0.3 \mathrm{mg} / \mathrm{dL}(\geq 26.4 \mu \mathrm{mol} / \mathrm{L})$ in less than 48 hours or a percentage increase in $\mathrm{sCr}$ of at least $50 \%$ (a minimum increase of 1.5 from baseline) in less than seven days ${ }^{19}$. In addition, a new algorithm based for managing the treatment of AKI in patients with ESLD (Fig. 1) ${ }^{19}$ has been proposed. This algorithm is related to the stages of AKI and based on several prospective studies ${ }^{14,20-23}$.

A controversial issue is how to diagnose various types of AKI in patients with ESLD (Table 2). It may be possible to exclude both the post-renal and the pre-renal types because the former type is relatively infrequent and the latter should be diagnosed and treated by the measures envisaged by the previously mentioned new algorithm. The crux of the problem, therefore, relates to differentiating between (HRS)-AKI and acute tubular necrosis (ATN) or intrinsic AKI. Usually in clinical practice, it is possible to determine whether the patient's condition is (HRS)-AKI or (ATN)-AKI by applying the diagnostic criteria for HRS, according to the latest ICA consensus.

\section{Prognostic value of AKI in patients with ESLD}

Renal dysfunction has been demonstrated as a powerful predictor of morbidity and mortality in patients with ESLD. Indeed, the reported mortality of cirrhotic patients with AKI is as high as $90 \%$ in some studies ${ }^{24}$. This high mortality rate correlates with the initial severity of AKI and the extent to which appropriate treatment can reverse it ${ }^{19}$. The cause of renal failure also affects the patient's prognosis. It has been demonstrated that the three- 
month survival probability is $73 \%$ for parenchymal nephropathy, $46 \%$ for hypovolemiainduced AKI, 31\% for renal failure associated with infection, and only $15 \%$ for HRS ${ }^{25}$.

Pre-LT kidney dysfunction also has an impact on post-LT prognosis ${ }^{26}$. The survival benefit of LT declines as the pre-transplant $\mathrm{sCr}$ level increases ${ }^{27}$.

\section{Risk Factors for AKI}

Pre-operative risk factors

Identified in large observational studies, the main pre-operative risk factors for postoperative AKI in LT candidates include age, pre-existing co-morbidities (diabetes mellitus and systemic hypertension), severity of liver disease ${ }^{28}$ and obesity ${ }^{29-31}$. Pre-existing renal disease has been identified as an independent risk factor in some studies ${ }^{32}$, whereas other studies suggest that HRS may provide some protection against renal dysfunction after LT, if RRT was performed before LT ${ }^{31,33}$. Severe pre-transplant hyponatremia has recently been identified as correlating with a high incidence of post-operative AKI. The pathophysiological mechanisms are still under debate, and it is unclear whether hyponatremia is an independent risk factor for post-operative AKI or a consequence of pre-clinical renal impairment that went undetected prior to $\mathrm{LT}^{34}$.

\section{Intra-operative risk factors}

Intra-operative blood loss and subsequent blood transfusion (especially packed red blood cells and fresh frozen plasma), hemodynamic variables (mean arterial pressure, pulmonary capillary wedge pressure, systemic vascular resistance), and intra-operative hypovolemia ${ }^{35}$ are the main risk factors for AKI identified by most studies. The effect of 
donor graft remains uncertain, but in some studies, warm ischemic time and donation after cardiac death are identified as the main independent risk factors ${ }^{36,37}$.

\section{Post-operative risk factors}

Literature focusing on risk factors for AKI in the early post-operative period is limited. However, the need for surgical re-intervention, hypoalbuminemia, poor graft function, and immunosuppression therapy seem to be the main risk factors for renal dysfunction after $\mathrm{LT}^{38,39}$.

\section{Biomarkers}

In order to be useful, a renal biomarker must detect injury rapidly, must be highly sensitive and specific, and its level should correlate with the extent of injury ${ }^{40}$. Ideally, a biomarker for AKI is not elevated in chronic kidney disease or with pre-renal azotemia. In addition, there is no consensus regarding whether urinary or plasma markers are more useful. A plasma biomarker can detect renal injury even if the patient is anuric, and its level does not need to be corrected for dilution by, for example, the use of a diuretic. However, urine markers are generally considered more specific for detection of renal injury and less likely to be contaminated by release from other organs than the kidney. Considering these requirements, multiple novel biomarkers have been tested in different scenarios related to renal ischemia-reperfusion injury ${ }^{41}$.

\section{Neutrophil Gelatinase-Associated Lipocalin (NGAL)}

NGAL is a $23 \mathrm{kD}$ protein that is rapidly up-regulated and can be detected early after renal ischemia-reperfusion injury. Several authors evaluating urinary NGAL as a marker of 
renal injury after $\mathrm{LT}^{42-44}$ report results similar to those reported for other situations in which AKI occurs, with areas under the receiver-characteristics curve of $0.8^{42}$ and $0.87^{44}$ for urinary NGAL and 0.79 for plasma NGAL ${ }^{43}$. NGAL can be measured using point-of-care devices in the urine (ARCHITECT ${ }^{\circledR}$ analyzer, Abbott Diagnostics) and blood (Alere Triage ${ }^{\circledR}$ NGAL test) and by using routine chemistry analyzers (NGAL Test ${ }^{\mathrm{TM}}$, BioPorto Diagnostics). These tests are approved for clinical use in Europe. However, FDA approval in the United States is pending.

There is no evidence to date that routine measurement of either urinary or plasma NGAL improves outcomes after LT. However, in combination with more conventional markers, NGAL measurements may help determine the severity of renal injury immediately after surgery.

\section{Cystatin C}

Cystatin $\mathrm{C}$ is a low molecular protein secreted by all nucleated cells and filtrated but not reabsorbed by the kidney. Unlike sCr, its level reflects the GFR independent of muscle mass, although cystatin $\mathrm{C}$ increases with age ${ }^{45}$. Given that it is not a marker of renal injury but of renal function, cystatin $\mathrm{C}$ cannot necessarily be compared with the other renal biomarkers. Compared with $\mathrm{sCr}$, cystatin $\mathrm{C}$ has been shown to correlate better with GFR after $\operatorname{LT}^{46,47}$.

\section{Other markers}

Two small studies investigated the role of urinary and plasma interleukins such as IL6, IL-8, and IL-18 ${ }^{48}$ and of liver-type fatty acid-binding protein ${ }^{49}$ in LT recipients. The studies demonstrate that these markers predict AKI with a level of accuracy similar to that 
reported for urinary NGAL. These and other markers, such as Kidney Injury Molecule-1 (KIM-1), have not been evaluated in larger studies of LT patients.

\section{Renal biomarker as a clinical tool}

In Europe, NGAL and Nephrocheck, both point-of-care urinary tests that each measure two cell-cycle arrest biomarkers (i.e., TIMP-2 and IGFBP7), are approved for clinical use. In the United States, only Nephrocheck is currently approved by the FDA. Approval for the measurement of plasma and urinary NGAL is pending. Nephrocheck has not been evaluated in LT recipients.

\section{LICAGE expert panel conclusions on biomarkers}

- There is currently no evidence that routine measurement of renal biomarkers after LT improves outcomes. However, in specific clinical situations, measuring renal biomarkers may aid in the decision-making process regarding how to initiate calcineurin inhibitors after LT (2B).

- Urinary NGAL should be considered first, as it is the most widely analyzed of the approved biomarkers (2C).

- Nephrocheck, even though approved in the US and Europe, should not be used in the LT population and requires further validation (1C)

- Cystatin C may be a useful tool to assess GFR in addition to or instead of sCr. (2B)

\section{Prevention of AKI}


Patients with ESLD are at high risk of developing AKI, which, in turn is associated with a worse outcome in comparison with patients without renal dysfunction ${ }^{50,51}$. Taking into consideration the risk of developing AKI and the difficulty of early AKI identification, the prevention of AKI should be prioritized in patients with ESLD.

\section{General principles}

The general principles of AKI prevention have recently been updated for all patients at risk ${ }^{52}$ and specifically for cirrhotic patients ${ }^{19}$. The LICAGE expert panel's recommendations are as follows:

- discontinuing potentially nephrotoxic agents, including NSAIDs and vasodilators, when possible: (1C)

- decreasing or withdrawing diuretic therapy and reviewing antimicrobial medications, particularly aminoglycosides and amphotericin: (1C)

- monitoring the patient's urine output and sCr closely: (1C)

- improving the hemodynamics by using volume adjustment in patients with clinically suspected hypovolemia and achieving adequate perfusion pressure using pressers as indicated: (1B)

- recognizing and treating bacterial infections promptly: (1B)

- considering avoiding and/or using alternatives to radiocontrast procedures: (1B)

\section{Specific measures}

There are a number of specific measures that may help to prevent AKI in ESLD patients: 


\section{$\underline{\text { Treatment of spontaneous bacterial peritonitis (SBP) }}$}

The LICAGE panel recommends the timely recognition and treatment of bacterial infections as one of most important therapeutic options for preventing AKI (1B). In patients with ESLD who also have SBP, this treatment includes albumin infusion in addition to antimicrobial medications. It has been demonstrated that this intervention helps to decrease the development of renal failure, thereby improving the survival rate ${ }^{53}$.

\section{$\underline{\text { Administering albumin after paracentesis }}$}

The LICAGE panel recommends the infusion of albumin at the time of large-volume paracentesis, as it decreases the incidence of post-paracentesis circulatory dysfunction and improves the patient's chances of survival (1B) ${ }^{54}$.

\section{Contrast-induced AKI}

The LICAGE panel recommends the use of radiocontrast only if absolutely needed and at the lowest appropriate dose. Volume expansion with isotonic solutions (or preferably balanced electrolytes) at the time the contrast agent is administered is recommended. The use of oral N-acetyl cysteine (NAC) can also be considered, although there is no clear evidence that NAC administration is beneficial to this population of patients ${ }^{52}$. Contrast-induced nephropathy (CIN) has been challenged recently and extensively discussed in a review ${ }^{55}$. The authors concluded that CIN was over-diagnosed and more related to the severity of the patient's illness (sepsis, septic shock) and to the use of nephrotoxic drugs and some physiologic changes that favored the occurrence of AKI. In a retrospective study, patients were stratified into three risk-groups: low risk (serum creatinine $<1.5 \mathrm{mg} / \mathrm{dL}$ ), middle risk $(1.5-2.0 \mathrm{mg} / \mathrm{dL})$, and high risk $(>2 \mathrm{mg} / \mathrm{dL})$. A total of 157,140 scans of 53,439 patients 
were analyzed. After risk adjustment with a propensity score, contrast media was not found to be an independent risk factor for AKI ${ }^{56}$. The AKI was more related to diminished renal function and general poor patients' condition. Therefore, it seems doubtful that the intravenous use of contrast media causes acute renal failure in critically ill or cirrhotic patients.

\section{Pharmacologic prevention}

Many pharmacologic interventions such as a low doses of dopamine, fenoldopam, or atrial natriuretic peptide have been proposed for AKI prevention ${ }^{52}$. To date, however, none of these medications have been confirmed as a useful therapy, and none are recommended for use by the LICAGE panel.

\section{Intraoperative management}

No particular surgical technique, including the use of veno-venous bypass, has been proven to protect against the development of AKI ${ }^{57,58}$. The use of a low central venous pressure (CVP) technique may increase the risk of AKI ${ }^{59}$; however, this concern was not confirmed in a subsequent randomized controlled trial ${ }^{60}$. Also, the use of CVP or stroke volume variation to guide fluid replacement has not been demonstrated to reduce the incidence of $\mathrm{AKI}^{61}$.

\section{Immunosuppression}

It is well known that calcineurin inhibitors (CNIs) can significantly affect renal function. Unfortunately, no protective strategy has been established. Although there are a 
number of conflicting opinions regarding the potential renal risk mitigations by $\mathrm{CNI}$ minimization ${ }^{62}$, none of these are supported by evidence.

\section{Intra-operative renal support during liver transplantation}

Intra-operative continuous renal replacement treatment (IO-CRRT) has become available only relatively recently. Thus, there is a paucity of data available on the benefits of IO-CRRT; the literature is mostly case reports and retrospective studies ${ }^{63,}{ }^{64}$. Impaired kidney function during LT used to be managed using strict fluid restriction, vasopressor support, and continuous metabolic adjustment. However, expanding the indications of LT and changes in organ allocation policy are accompanied by a significantly increased number of patients with pre-existing renal dysfunction. In this setting, the use of IO-CRRT seems to be very helpful for patient management.

To date, three retrospective studies demonstrating that IO-CRRT can be performed safely with significant benefits for the patients have been published ${ }^{65-67}$.

\section{Decision}

The decision to initiate IO-CRRT is made by the transplant team (intensivist, anesthesiologist, surgeon, and nephrologist) and is based on pre-operative kidney function, the severity of the condition, anticipated poor tolerance of intra-operative management (transfusion requirements, fluid administration, donor graft reperfusion), and/or anticipated need for post-operative CRRT ${ }^{67}$.

Intra-operative hemodialysis can be administered by either an ICU staff member or a nephrology nurse. Arterial blood gas (ABG) analysis should be performed periodically and 
the results should be discussed with the anesthesiologist, who is responsible for fluid and electrolyte management intra-operatively.

\section{Dialysate-replacement solutions}

The decision whether to add bicarbonate or potassium and in what quantity or a dialysate or replacement solution should be made on a patient-by-patient basis. Any anticoagulates are not usually used in patients undergoing LT with an acceptable filter circuit lifespan, since there is an increased risk of bleeding associated with heparin and the potential toxicity associated with citrate ${ }^{65}$. In the operating room, dialysis machines run with blood flow rates of $200-300 \mathrm{~mL} /$ hour and dialysate flow rates of $200-300 \mathrm{~mL} /$ hour $^{65}$.

\section{Metabolic acidosis}

Lactic acidosis is a common condition in patients during LT ${ }^{68}$. Lack of lactate metabolism or excessive production of lactate are common causes of this phenomenon. During the anhepatic phase, all hepatic vessels are either partially or completely clamped, which results in significant lactate accumulation. In the neohepatic phase, lactate begins to metabolize at about 60 minutes after graft reperfusion. Lactic acidosis becomes more prominent in the presence of impaired renal function. This concomitant renal impairment makes managing lactic acidosis extremely difficult. In this context, IOCRRT would be very helpful.

If the patient is under refractory acidosis, further therapeutic options can be instituted by increasing bicarbonate content in the dialysate from $35 \mathrm{mEq} / \mathrm{L}$ to $40 \mathrm{mEq} / \mathrm{L}$. In such a case, blood flow should also be increased from $200 \mathrm{~mL} / \mathrm{h}$ to $300 \mathrm{~mL} / \mathrm{h}$ or even higher in order to provide a sufficient transfer of bicarbonate molecules through the filter to the patient ${ }^{65}$. 


\section{Hyperkalemia}

Hyperkalemia occurs very frequently during LT. In patients with concomitant kidney injury, hyperkalemia can cause very serious problems during graft reperfusion including hemodynamic derangements ${ }^{69}$ such as bradycardia, hypotension, and/or a rhythm disorder such as atrio-ventricular block ${ }^{70}$. The standard concentration of potassium in a dialysate bag is $2 \mathrm{mEq} / \mathrm{L}$. In cases of severe hyperkalemia, however, potassium-free dialysate should be used.

\section{Effect of intra-operative dialysis on volume management}

ESLD is associated with increased pressure and blood shunting in the splanchnic area 71, which makes hemodynamic management very difficult - especially in the presence of kidney failure. Patients with ESLD have high vascular compliance combined with increased pooling of blood in the splanchnic circulation. This is associated with a minimal increase in CVP, although the patient appears hypervolemic ${ }^{71}$. Such a characteristic of hemodynamics should be considered during LT when the volume status is usually monitored by CVP.

There is an ongoing discussion regarding whether the patient should be on the "dry" side to avoid graft congestion or on the "wet" side to preserve or improve kidney function ${ }^{72}$, 73. The anhepatic phase, when the inferior vena cava (IVC) is clamped, is considered one of the most challenging parts of LT. After the portal vein and the IVC are clamped, there is a decrease of around $50-60 \%$ of the venous return, which is accompanied by a significant drop in systemic blood pressure. At this stage, a volume challenge together with a vasopressor is required to maintain mean arterial pressure at $60-70 \mathrm{mmHg}$. However, after declamping, sudden volume load may result in right heart decompensation. In such a complicated 
hemodynamic situation, IO-CRRT can achieve an optimum fluid balance during LT and help ensure hemodynamic stability.

\section{Recommendation}

The LICAGE panel recommends IO-CRRT as a very helpful tool for managing the treatment of patients with impaired kidney function during LT. All the complications associated with kidney dysfunction such as acidosis, hyperkalemia, and volume overload can be treated very safely. (1B)

\section{Timing of post-operative renal replacement therapy (RRT)}

The optimal timing for administering RRT in patients with AKI post-operatively is not well-defined. It has been demonstrated that early implementation of RRT can help achieve better control of fluid and electrolyte balance in selected patient populations than later implementation of RRT ${ }^{74-76}$. At the same time, however, early initiation of RRT has been discouraged because of the following potential negative consequences:

1. Complications associated with establishing vascular access, including bleeding, pneumothorax, and infection

2. Slower renal recovery after surgery 77,78

In 2012, the KDIGO Working Group defined three emergency indications for the initiation of $\operatorname{RRT}^{18}$ :

1. Life-threatening electrolyte disorders

2. Metabolic acidosis that cannot be controlled with conservative therapy

3. Hypervolemia, particularly when resulting in refractory pulmonary edema 


\section{General Considerations}

The RIFLE (Risk, Injury, Failure, Loss, and End-stage kidney disease) criteria are most frequently used to determine when to initiate RRT. The current literature, however, presents no definitive recommendation concerning the timing of RRT initiation. Several retrospective studies have demonstrated a benefit associated with early RRT initiation. Carl et al. reviewed the survival of septic patients with AKI. The timing of RRT initiation in this study was based on blood urea nitrogen (BUN) level ${ }^{79}$. Early initiation of RRT was associated with a superior 28-day and one-year survival rate ${ }^{80}$.

In a prospective trial in a surgical ICU setting, Shiao et al. demonstrated that starting RRT at an advanced RIFLE stage after major abdominal surgery is associated with higher mortality (OR 1.85) ${ }^{81}$. However, this finding has not been confirmed by other investigators 75. In another retrospective study, Shum et al. evaluated patient outcomes in the setting of severe sepsis and septic shock. The timing of RRT initiation was also determined based on RIFLE criteria ${ }^{82}$. Early initiation of RRT (stage R) was not found to be superior in comparison to starting RRT later (stage I or F) in terms of mortality, dialysis requirements, or the Sequential Organ Failure Assessment (SOFA) score. It should be noted that patients in the late RRT group had significantly poorer kidney function compared with that of patients in the early RRT group, which was probably a confounding factor. A recent meta-analysis published by Karvellas et al. indicated that early dialysis has a beneficial effect ${ }^{83}$. The criteria for starting RRT, however, differed across all the studies included in the analysis. Initiation of RRT was either triggered by BUN, serum creatinine, RIFLE stage, or urine output, such that it was not possible to compare the results reported in these studies. 
Only a few studies focused on evaluating the use of RRT in the setting of liver failure/LT have been published. Wu et al. examined the use of continuous venous-venous hemofiltration in patients with post-operative liver and kidney failure ${ }^{84}$. They demonstrated that earlier initiation of RRT, based on pre-dialysis BUN level, is associated with improved ICU survival. In a retrospective study, Agopian et al. compared a variety of intra- and postoperative outcomes in patients who had received planned, emergency, or no intra-operative RRT. Patients with planned RRT had significantly fewer intra-operative complications than those who received emergency RRT ${ }^{66}$.

\section{Recommendations}

Based on the current literature, the LICAGE panel cannot give a general recommendation for beginning RRT at an early stage of AKI (1C). There is evidence, however, that initiating RRT earlier, i.e., at stage F or I (RIFLE criteria), than is usually the case at present, would be beneficial for some patients, particularly if the AKI is progressing rapidly ${ }^{85}$.

According to the KDIGO criteria, any decision pertaining to whether or not to begin RRT should be made based on a clinical assessment instead of on the sole basis of laboratory values such as those for serum creatinine or $\mathrm{BUN}^{18}$. It is our opinion that the final decision to initiate RRT must be based on both clinical considerations and laboratory values. As always, an individualized patient-specific approach should be used.

\section{Summary}

This position paper highlights current knowledge of kidney failure, including efforts to improve kidney function in LT patients. Pre- and post-operative risk factors for AKI are 
difficult to control; this is why the focus should be on intra-operative hemodynamics and avoiding nephrotoxic drugs (antibiotics and reduced use of CNI). Prospective randomized trials are needed to show the beneficial effect of intra-operative and/or post-operative early RRT. In this context, the new biomarkers would be helpful in identifying AKI earlier and would probably prevent dialysis-dependent kidney failure.

Key messages:

1. Diagnosis of AKI should be based on the KDIGO criteria.

2. Risk factors are already known and were stratified into pre-, intra-, and post-operative risk factors. The pre-operative risk factors are more related to the patient's predisposing factors and post-operative risk factors tend to be difficult to control (immunosuppression, reoperation due to bleeding, bile leak, poor graft function). Therefore, focusing on intra-operative risk factors would be important to maintain an adequate hemodynamics (MAP $\geq 70 \mathrm{mmHg}$ ) and to keep inferior vena cava clamping (warm ischemia time for kidneys) as short as possible.

3. Biomarkers to identify AKI at an early stage are available; however, there is a lack of robust data that indicates their beneficial effect in terms of avoiding AKI after LT.

4. Intraoperative RRT may be beneficial in some selective cases; however, a general recommendation cannot be given.

5. Timing of dialysis either pre- or post-operatively is still under debate. There are some promising studies that associate starting dialysis earlier with a better outcome, but it has not been proven with RCTs. The LICAGE panel, however, would prefer early initiation of dialysis. 


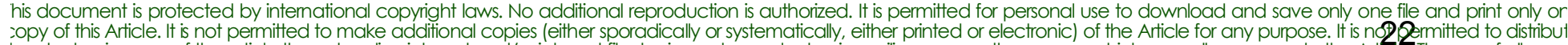

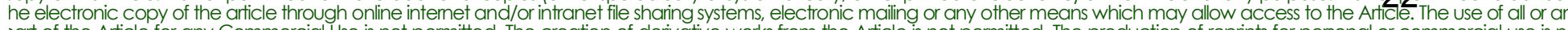




\section{References}

1. Lewington AJ, Cerda J, Mehta RL. Raising awareness of acute kidney injury: a global perspective of a silent killer. Kidney international. 2013; 84:457-67.

2. Zhu M, Li Y, Xia Q, Wang S, Qiu Y, Che M, et al. Strong impact of acute kidney injury on survival after liver transplantation. Transplant Proc. 2010; 42:3634-8.

3. Iwakiri Y, Shah V, Rockey DC. Vascular pathobiology in chronic liver disease and cirrhosis - current status and future directions. J Hepatol. 2014; 61:912-24.

4. Epstein M, Levinson R, Sancho J, Haber E, Re R. Characterization of the reninaldosterone system in decompensated cirrhosis. Circulation research. 1977; 41:81829.

5. Vallance P, Moncada S. Hyperdynamic circulation in cirrhosis: a role for nitric oxide? Lancet. 1991; 337:776-8.

6. Saner FH, Neumann T, Canbay A, Treckmann JW, Hartmann M, Goerlinger K, et al. High brain-natriuretic peptide level predicts cirrhotic cardiomyopathy in liver transplant patients. Transpl Int. 2011; 24:425-32.

7. Ivarsen P, Frokiaer J, Aagaard NK, Hansen EF, Bendtsen F, Nielsen S, et al. Increased urinary excretion of aquaporin 2 in patients with liver cirrhosis. Gut. 2003; 52:1194-9.

8. Gines P, Schrier RW. Renal failure in cirrhosis. N Engl J Med. 2009; 361:1279-90.

9. Arroyo V, Colmenero J. Ascites and hepatorenal syndrome in cirrhosis: pathophysiological basis of therapy and current management. J Hepatol. 2003; 38 Suppl 1:S69-89.

10. Leber B, Spindelboeck W, Stadlbauer V. Infectious complications of acute and chronic liver disease. Semin Respir Crit Care Med. 2012; 33:80-95.

11. Jalan R, Fernandez J, Wiest R, Schnabl B, Moreau R, Angeli P, et al. Bacterial infections in cirrhosis: a position statement based on the EASL Special Conference 2013. J Hepatol. 2014; 60:1310-24.

12. Lee HT, Park SW, Kim M, D'Agati VD. Acute kidney injury after hepatic ischemia and reperfusion injury in mice. Lab Invest. 2009; 89:196-208.

13. Leithead JA, Hayes PC, Ferguson JW. Review article: advances in the management of patients with cirrhosis and portal hypertension-related renal dysfunction. Alimentary pharmacology \& therapeutics. 2014; 39:699-711.

14. Tsien CD, Rabie R, Wong F. Acute kidney injury in decompensated cirrhosis. Gut. 2013; 62:131-7.

15. Uguen T, Jezequel C, Ropert M, Houssel-Debry P, Latournerie M, Laine F, et al. Pretransplant renal function according to $\mathrm{CKD}$-EPI cystatin $\mathrm{C}$ equation is a prognostic factor of death after liver transplantation. Liver Int. 2016; 36:547-54.

16. Salerno F, Gerbes A, Gines P, Wong F, Arroyo V. Diagnosis, prevention and treatment of hepatorenal syndrome in cirrhosis. Gut. 2007; 56:1310-8.

17. Arroyo V, Gines P, Gerbes AL, Dudley FJ, Gentilini P, Laffi G, et al. Definition and diagnostic criteria of refractory ascites and hepatorenal syndrome in cirrhosis.

International Ascites Club. Hepatology. 1996; 23:164-76.

18. KDIGO Clinical Practice Guideline for Acute Kidney Injury. Kidney Int Suppl. 2012; 2:1-138. 
19. Angeli P, Gines P, Wong F, Bernardi M, Boyer TD, Gerbes A, et al. Diagnosis and management of acute kidney injury in patients with cirrhosis: revised consensus recommendations of the International Club of Ascites. Journal of hepatology. 2015; 62:968-74.

20. Wong F, O'Leary JG, Reddy KR, Patton H, Kamath PS, Fallon MB, et al. New consensus definition of acute kidney injury accurately predicts 30-day mortality in patients with cirrhosis and infection. Gastroenterology. 2013; 145:1280-8 e1.

21. de Carvalho JR, Villela-Nogueira CA, Luiz RR, Guzzo PL, da Silva Rosa JM, Rocha $\mathrm{E}$, et al. Acute kidney injury network criteria as a predictor of hospital mortality in cirrhotic patients with ascites. Journal of clinical gastroenterology. 2012; 46:e21-6.

22. Fagundes C, Barreto R, Guevara M, Garcia E, Sola E, Rodriguez E, et al. A modified acute kidney injury classification for diagnosis and risk stratification of impairment of kidney function in cirrhosis. J Hepatol. 2013; 59:474-81.

23. Belcher JM, Garcia-Tsao G, Sanyal AJ, Bhogal H, Lim JK, Ansari N, et al. Association of AKI with mortality and complications in hospitalized patients with cirrhosis. Hepatology. 2013; 57:753-62.

24. Cholongitas E, Calvaruso V, Senzolo M, Patch D, Shaw S, O'Beirne J, et al. RIFLE classification as predictive factor of mortality in patients with cirrhosis admitted to intensive care unit. Journal of gastroenterology and hepatology. 2009; 24:1639-47.

25. Martin-Llahi M, Guevara M, Torre A, Fagundes C, Restuccia T, Gilabert R, et al. Prognostic importance of the cause of renal failure in patients with cirrhosis. Gastroenterology. 2011; 140:488-96 e4.

26. Karapanagiotou A, Kydona C, Dimitriadis C, Sgourou K, Giasnetsova T, Fouzas I, et al. Acute kidney injury after orthotopic liver transplantation. Transplant Proc. 2012; 44:2727-9.

27. Nair S, Verma S, Thuluvath PJ. Pretransplant renal function predicts survival in patients undergoing orthotopic liver transplantation. Hepatology. 2002; 35:1179-85.

28. Gonwa TA, McBride MA, Anderson K, Mai ML, Wadei H, Ahsan N. Continued influence of preoperative renal function on outcome of orthotopic liver transplant (OLTX) in the US: where will MELD lead us? Am J Transplant. 2006; 6:2651-9.

29. Barreto AG, Daher EF, Silva Junior GB, Garcia JH, Magalhaes CB, Lima JM, et al. Risk factors for acute kidney injury and 30-day mortality after liver transplantation. Ann Hepatol. 2015; 14:688-94.

30. Biancofiore G, Davis CL. Renal dysfunction in the perioperative liver transplant period. Curr Opin Organ Transplant. 2008; 13:291-7.

31. Shusterman B, McHedishvili G, Rosner MH. Outcomes for hepatorenal syndrome and acute kidney injury in patients undergoing liver transplantation: a single-center experience. Transplant Proc. 2007; 39:1496-500.

32. Hilmi IA, Damian D, Al-Khafaji A, Planinsic R, Boucek C, Sakai T, et al. Acute kidney injury following orthotopic liver transplantation: incidence, risk factors, and effects on patient and graft outcomes. Br J Anaesth. 2015; 114:919-26.

33. Nadim MK, Genyk YS, Tokin C, Fieber J, Ananthapanyasut W, Ye W, et al. Impact of the etiology of acute kidney injury on outcomes following liver transplantation: acute tubular necrosis versus hepatorenal syndrome. Liver Transpl. 2012; 18:539-48.

34. Cimen S, Guler S, Ayloo S, Molinari M. Implications of Hyponatremia in Liver Transplantation. Journal of clinical medicine. 2014; 4:66-74. 
35. Aksu Erdost H, Ozkardesler S, Ocmen E, Avkan-Oguz V, Akan M, Iyilikci L, et al. Acute Renal Injury Evaluation After Liver Transplantation: With RIFLE Criteria. Transplant Proc. 2015; 47:1482-7.

36. Hilmi IA, Damian D, Al-Khafaji A, Sakai T, Donaldson J, Winger DG, et al. Acute kidney injury after orthotopic liver transplantation using living donor versus deceased donor grafts: A propensity score-matched analysis. Liver Transpl. 2015; 21:1179-85.

37. Ruebner RL, Reese PP, Abt PL. Donation after cardiac death liver transplantation is associated with increased risk of end-stage renal disease. Transpl Int. 2014; 27:126371.

38. Popescu M, G. D, S. D, Tomescu D. Perioperative Risk factors for acute kidney injury and chronic disease in liver transplant patients. Intensive Care Med. 2014; 40 (suppl 1):S 109.

39. Sang BH, Bang JY, Song JG, Hwang GS. Hypoalbuminemia Within Two Postoperative Days Is an Independent Risk Factor for Acute Kidney Injury Following Living Donor Liver Transplantation: A Propensity Score Analysis of 998 Consecutive Patients. Crit Care Med. 2015; 43:2552-61.

40. McIlroy DR, Wagener G, Lee HT. Biomarkers of acute kidney injury: an evolving domain. Anesthesiology. 2010; 112:998-1004.

41. Vanmassenhove J, Vanholder R, Nagler E, Van Biesen W. Urinary and serum biomarkers for the diagnosis of acute kidney injury: an in-depth review of the literature. Nephrology, dialysis, transplantation : official publication of the European Dialysis and Transplant Association - European Renal Association. 2013; 28:254-73.

42. Wagener G, Minhaz M, Mattis FA, Kim M, Emond JC, Lee HT. Urinary neutrophil gelatinase-associated lipocalin as a marker of acute kidney injury after orthotopic liver transplantation. Nephrology, dialysis, transplantation : official publication of the European Dialysis and Transplant Association - European Renal Association. 2011; 26:1717-23.

43. Niemann CU, Walia A, Waldman J, Davio M, Roberts JP, Hirose R, et al. Acute kidney injury during liver transplantation as determined by neutrophil gelatinaseassociated lipocalin. Liver transplantation : official publication of the American Association for the Study of Liver Diseases and the International Liver Transplantation Society. 2009; 15:1852-60.

44. Portal AJ, McPhail MJ, Bruce M, Coltart I, Slack A, Sherwood R, et al. Neutrophil gelatinase--associated lipocalin predicts acute kidney injury in patients undergoing liver transplantation. Liver Transpl. 2010; 16:1257-66.

45. Knight EL, Verhave JC, Spiegelman D, Hillege HL, de Zeeuw D, Curhan GC, et al. Factors influencing serum cystatin $\mathrm{C}$ levels other than renal function and the impact on renal function measurement. Kidney international. 2004; 65:1416-21.

46. Biancofiore G, Pucci L, Cerutti E, Penno G, Pardini E, Esposito M, et al. Cystatin C as a marker of renal function immediately after liver transplantation. Liver Transpl. 2006; 12:285-91.

47. Schuck O, Gottfriedova H, Maly J, Jabor A, Stollova M, Bruzkova I, et al. Glomerular filtration rate assessment in individuals after orthotopic liver transplantation based on serum cystatin C levels. Liver Transpl. 2002; 8:594-9.

48. Sirota JC, Walcher A, Faubel S, Jani A, McFann K, Devarajan P, et al. Urine IL-18, NGAL, IL-8 and serum IL-8 are biomarkers of acute kidney injury following liver transplantation. BMC nephrology. 2013; 14:17. 
49. Li Y, Zhu M, Xia Q, Wang S, Qian J, Lu R, et al. Urinary neutrophil gelatinaseassociated lipocalin and L-type fatty acid binding protein as diagnostic markers of early acute kidney injury after liver transplantation. Biomarkers. 2012; 17:336-42.

50. Cholongitas E, Senzolo M, Patch D, Shaw S, O'Beirne J, Burroughs AK. Cirrhotics admitted to intensive care unit: the impact of acute renal failure on mortality. Eur J Gastroenterol Hepatol. 2009; 21:744-50.

51. Razonable RR, Findlay JY, O'Riordan A, Burroughs SG, Ghobrial RM, Agarwal B, et al. Critical care issues in patients after liver transplantation. Liver Transpl. 2011; 17:511-27.

52. Group. KDIGOKAKIW. KDIGO Clinical Practice Guideline for Acute Kidney Injury. Kidney International supplement. 2012; 2:1-138.

53. Salerno F, Navickis RJ, Wilkes MM. Albumin infusion improves outcomes of patients with spontaneous bacterial peritonitis: a meta-analysis of randomized trials. Clin Gastroenterol Hepatol. 2013; 11:123-30 e1.

54. Bernardi M, Caraceni P, Navickis RJ, Wilkes MM. Albumin infusion in patients undergoing large-volume paracentesis: a meta-analysis of randomized trials. Hepatology. 2012; 55:1172-81.

55. Davenport MS, Cohan RH, Khalatbari S, Ellis JH. The challenges in assessing contrast-induced nephropathy: where are we now? AJR American journal of roentgenology. 2014; 202:784-9.

56. McDonald RJ, McDonald JS, Bida JP, Carter RE, Fleming CJ, Misra S, et al. Intravenous contrast material-induced nephropathy: causal or coincident phenomenon? Radiology. 2013; 267:106-18.

57. Gurusamy KS, Koti R, Pamecha V, Davidson BR. Veno-venous bypass versus none for liver transplantation. The Cochrane database of systematic reviews. 2011:CD007712.

58. Gurusamy KS, Pamecha V, Davidson BR. Piggy-back graft for liver transplantation. The Cochrane database of systematic reviews. 2011:CD008258.

59. Schroeder RA, Collins BH, Tuttle-Newhall E, Robertson K, Plotkin J, Johnson LB, et al. Intraoperative fluid management during orthotopic liver transplantation. J Cardiothorac Vasc Anesth. 2004; 18:438-41.

60. Feng ZY, Xu X, Zhu SM, Bein B, Zheng SS. Effects of low central venous pressure during preanhepatic phase on blood loss and liver and renal function in liver transplantation. World J Surg. 2010; 34:1864-73.

61. Wang SC, Teng WN, Chang KY, Susan Mandell M, Ting CK, Chu YC, et al. Fluid management guided by stroke volume variation failed to decrease the incidence of acute kidney injury, 30-day mortality, and 1-year survival in living donor liver transplant recipients. J Chin Med Assoc. 2012; 75:654-9.

62. Saner FH, Cicinnati VR, Sotiropoulos G, Beckebaum S. Strategies to prevent or reduce acute and chronic kidney injury in liver transplantation. Liver Int. 2012; 32:179-88.

63. Parmar A, Bigam D, Meeberg G, Cave D, Townsend DR, Gibney RT, et al. An evaluation of intraoperative renal support during liver transplantation: a matched cohort study. Blood Purif. 2011; 32:238-48.

64. Bellomo R, Harris C, Kang Y, Daniel E, Fung JJ, Bronsther O. Combined venovenous bypass and high volume hemofiltration during orthotopic liver transplantation. ASAIO journal. 1993; 39:954-6. 
65. Nadim MK, Annanthapanyasut W, Matsuoka L, Appachu K, Boyajian M, Ji L, et al. Intraoperative hemodialysis during liver transplantation: a decade of experience.

Liver Transpl. 2014; 20:756-64.

66. Agopian VG, Dhillon A, Baber J, Kaldas FM, Zarrinpar A, Farmer DG, et al. Liver transplantation in recipients receiving renal replacement therapy: outcomes analysis and the role of intraoperative hemodialysis. Am J Transplant. 2014; 14:1638-47.

67. Townsend DR, Bagshaw SM, Jacka MJ, Bigam D, Cave D, Gibney RT. Intraoperative renal support during liver transplantation. Liver Transpl. 2009; 15:738.

68. Vitin A, Muczynski K, Bakthavatsalam R, Martay K, Dembo G, Metzner J. Treatment of severe lactic acidosis during the pre-anhepatic stage of liver transplant surgery with intraoperative hemodialysis. Journal of clinical anesthesia. 2010; 22:46672.

69. Xia VW, Ghobrial RM, Du B, Chen T, Hu KQ, Hiatt JR, et al. Predictors of hyperkalemia in the prereperfusion, early postreperfusion, and late postreperfusion periods during adult liver transplantation. Anesth Analg. 2007; 105:780-5.

70. Kim SH, Moon YJ, Lee S, Jeong SM, Song JG, Hwang GS. Atrioventricular conduction disturbances immediately after hepatic graft reperfusion and their outcomes in patients undergoing liver transplantation. Liver Transpl. 2016.

71. Mukhtar A, Dabbous H. Modulation of splanchnic circulation: Role in perioperative management of liver transplant patients. World journal of gastroenterology : WJG. 2016; 22:1582-92.

72. Cywinski JB, Mascha E, You J, Argalious M, Kapural L, Christiansen E, et al. Central venous pressure during the post-anhepatic phase is not associated with early postoperative outcomes following orthotopic liver transplantation. Minerva anestesiologica. 2010; 76:795-804.

73. Feng ZY, Xu X, Zhu SM, Bein B, Zheng SS. Effects of low central venous pressure during preanhepatic phase on blood loss and liver and renal function in liver transplantation. World journal of surgery. 2010; 34:1864-73.

74. Acheampong A, Vincent JL. A positive fluid balance is an independent prognostic factor in patients with sepsis. Crit Care. 2015; 19:251.

75. Chou YH, Huang TM, Wu VC, Wang CY, Shiao CC, Lai CF, et al. Impact of timing of renal replacement therapy initiation on outcome of septic acute kidney injury. Critical care. 2011; 15:R134.

76. Ostermann M, Chang RW. Correlation between parameters at initiation of renal replacement therapy and outcome in patients with acute kidney injury. Critical care. 2009; 13:R175.

77. Elseviers MM, Lins RL, Van der Niepen P, Hoste E, Malbrain ML, Damas P, et al. Renal replacement therapy is an independent risk factor for mortality in critically ill patients with acute kidney injury. Crit Care. 2010; 14:R221.

78. Clec'h C, Gonzalez F, Lautrette A, Nguile-Makao M, Garrouste-Orgeas M, Jamali S, et al. Multiple-center evaluation of mortality associated with acute kidney injury in critically ill patients: a competing risks analysis. Crit Care. 2011; 15:R128.

79. Carl DE, Grossman C, Behnke M, Sessler CN, Gehr TW. Effect of timing of dialysis on mortality in critically ill, septic patients with acute renal failure. Hemodial Int. $2010 ; 14: 11-7$. 
80. Bouman CS, Oudemans-Van Straaten HM, Tijssen JG, Zandstra DF, Kesecioglu J. Effects of early high-volume continuous venovenous hemofiltration on survival and recovery of renal function in intensive care patients with acute renal failure: a prospective, randomized trial. Crit Care Med. 2002; 30:2205-11.

81. Shiao CC, Wu VC, Li WY, Lin YF, Hu FC, Young GH, et al. Late initiation of renal replacement therapy is associated with worse outcomes in acute kidney injury after major abdominal surgery. Critical care. 2009; 13:R171.

82. Shum HP, Chan KC, Kwan MC, Yeung AW, Cheung EW, Yan WW. Timing for initiation of continuous renal replacement therapy in patients with septic shock and acute kidney injury. Therapeutic apheresis and dialysis : official peer-reviewed journal of the International Society for Apheresis, the Japanese Society for Apheresis, the Japanese Society for Dialysis Therapy. 2013; 17:305-10.

83. Karvellas CJ, Farhat MR, Sajjad I, Mogensen SS, Leung AA, Wald R, et al. A comparison of early versus late initiation of renal replacement therapy in critically ill patients with acute kidney injury: a systematic review and meta-analysis. Critical care. 2011; 15:R72.

84. Wu VC, Ko WJ, Chang HW, Chen YS, Chen YW, Chen YM, et al. Early renal replacement therapy in patients with postoperative acute liver failure associated with acute renal failure: effect on postoperative outcomes. Journal of the American College of Surgeons. 2007; 205:266-76.

85. Basso F, Ricci Z, Cruz D, Ronco C. International survey on the management of acute kidney injury in critically ill patients: year 2007. Blood Purif. 2010; 30:214-20. 


\section{Notes}

All authors declare that they do not have any conflict of interest concerning this manuscript. 
Table 1. Current diagnostic criteria for acute kidney injury (AKI) in the general population and in patients with cirrhosis

Table 2: International Club of Ascites (ICA-AKI) new definitions for the diagnosis and management of acute kidney injury in patients with cirrhosis

Figure 1: Diagnosis and treatment algorithm for acute kidney injury. 


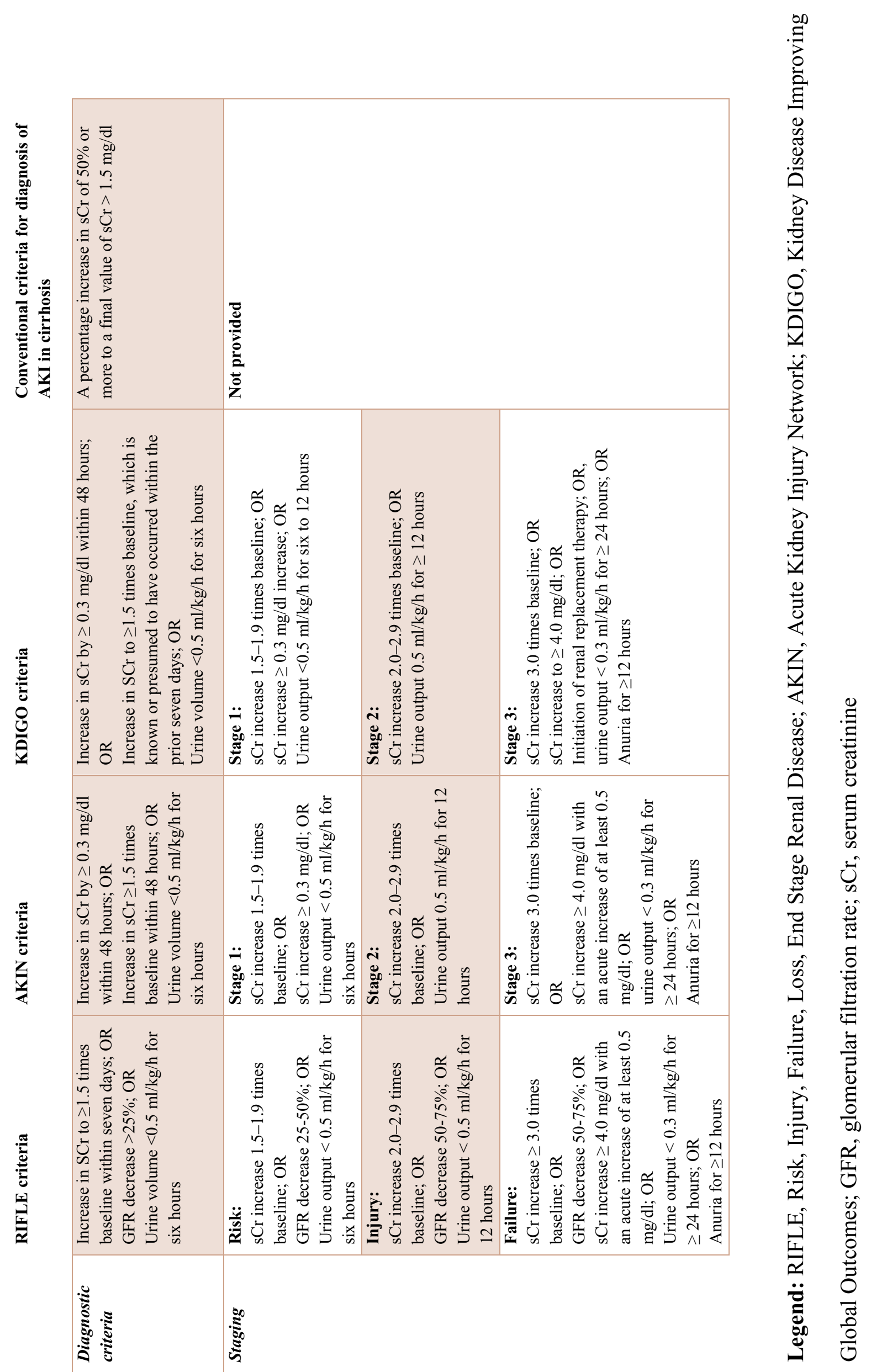




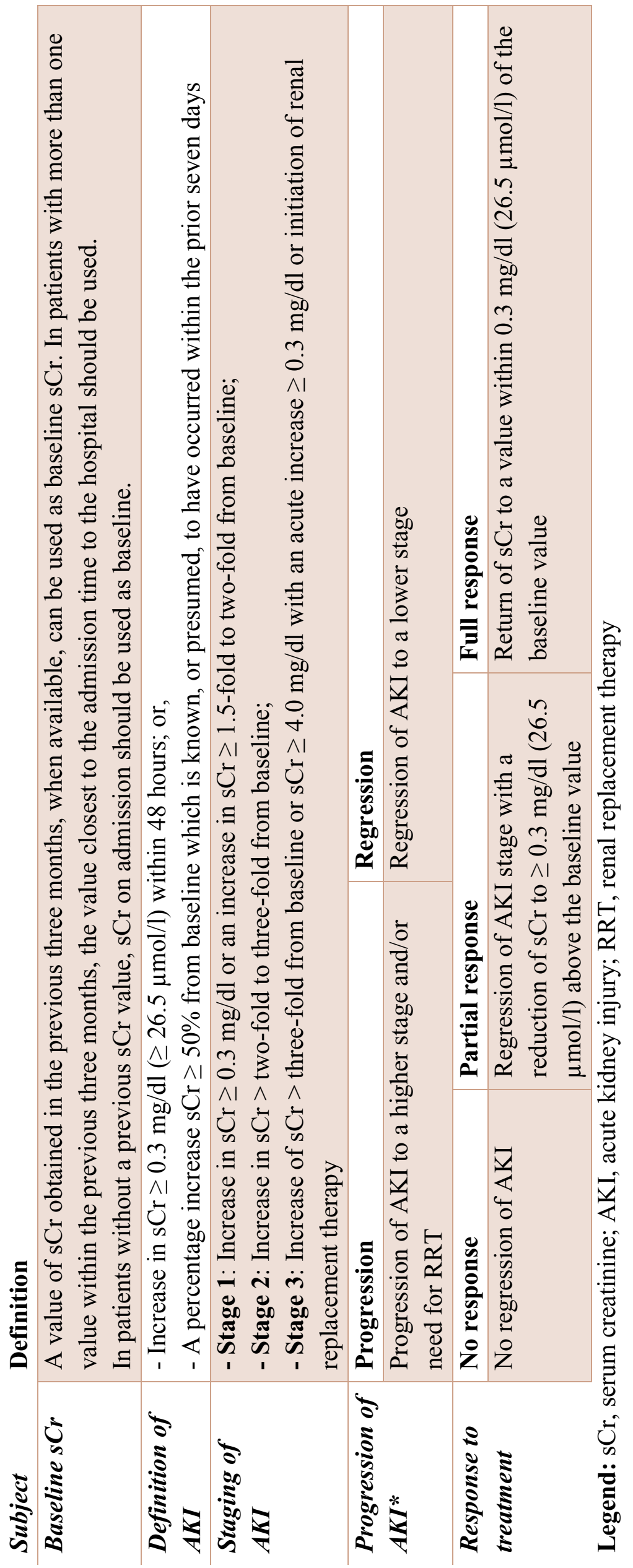




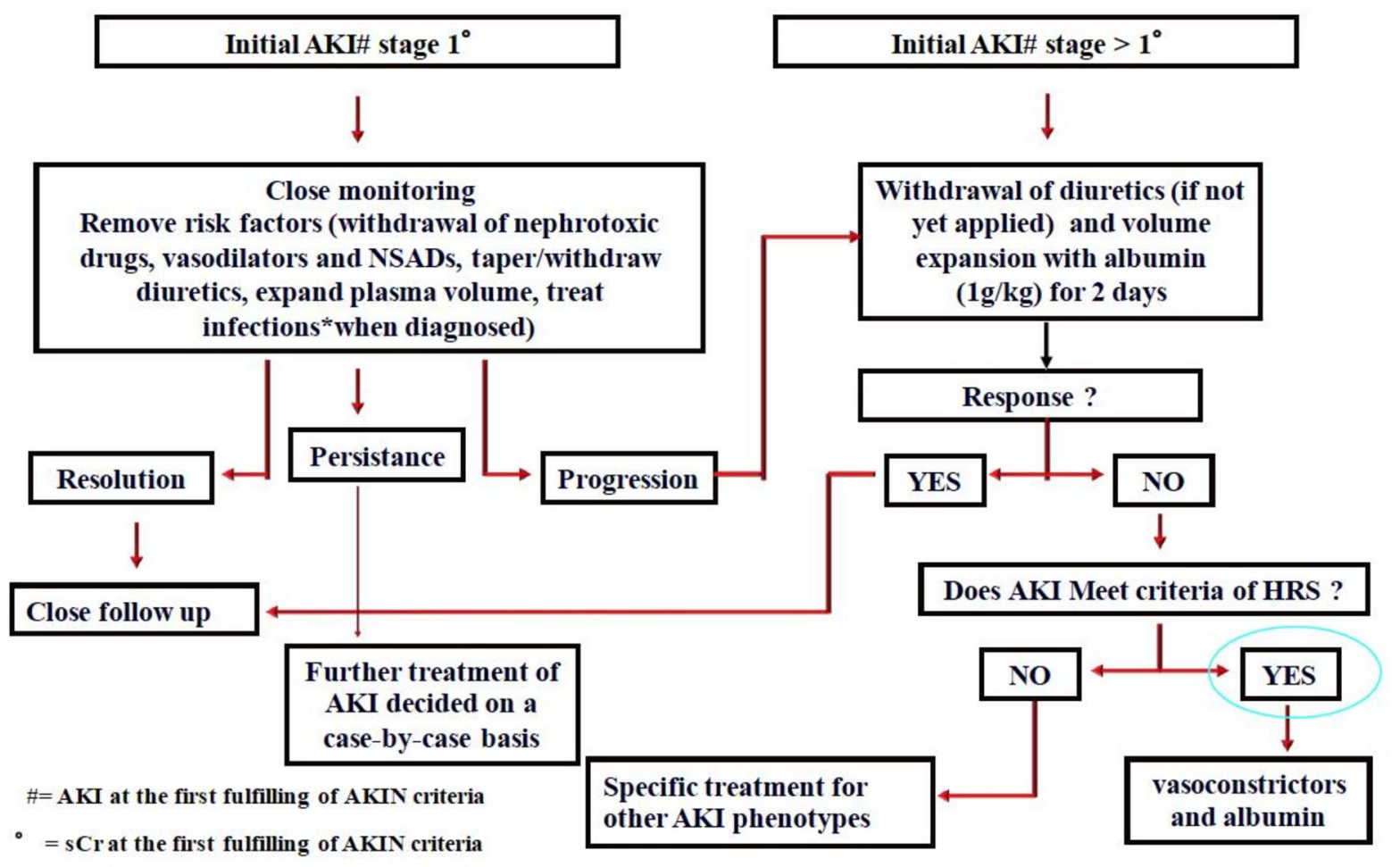

P. Angeli et al. on behalf of ICA J. Hepatol. 201562 : 968-974 